DOI 10.37882/2500-3682.2020.08.18

\title{
БАЗИСНЫЕ УБЕЖДЕНИЯ ЛИЧНОСТИ, ПРЕДСТАВЛЕНИЯ О СЕБЕ И ИХ ВЗАИМОСВЯЗЬ СО СТРАТЕГИЯМИ СОВЛАДАНИЯ
}

\section{BASIC BELIEFS OF A PERSONALITY, PERCEPTIONS AND THEIR RELATIONSHIP WITH COVERAGE STRATEGIES}

\section{E. Sekatskaya}

Summary: Goal. The purpose of the article is to study the relationship between deep personal beliefs and coping behavior. The results of a pilot study of 70 people are analyzed.

Procedure and methods of research. The theoretical basis is the cognitive-behavioral approach. The study used the questionnaire" Methods of coping behavior "by R. Lazarus, the method "Personal differential" and the Yanov-bulman scale of basic beliefs.

Research result. Based on the results, a conclusion is made about the relationship of deep beliefs, as well as personal properties with coping strategies. It is suggested that the personal characteristics of a person are more conscious than deep beliefs, so the connection with coping behavior is more pronounced.

The practical significance is to identify a person's ideas about himself, his beliefs and their relationship with the behavioral aspect, which is expressed in coping behavior.

Keywords: basic beliefs, coping strategies, assessment of personal qualities.

\author{
Секацкая Екатерина Олеговна \\ Аспирант, Российская академия народного хозяйства и \\ государственной службы при Президенте РФ \\ mus-ekaterina@yandex.ru
}

Аннотация: Цель. Целью статьи является изучение взаимосвязи между глубинными убеждениями личности и копинг поведением. Анализируются результаты пилотажного исследования в количестве 70 человек.

Процедура и методы исследования. Теоретической опорой выступает когнитивно-поведенческий подход. В исследовании использовался опросник «Способы совладающего поведения» Р. Лазаруса, методика «Личностный дифференциал» и шкала базисных убеждений Янов-Бульман.

Результаты исследования. На основании результатов, сделан вывод 0 взаимосвязи глубинных убеждений, а также личностных свойствах с копинг стратегиями. Высказывается предположение, о том, что личностные свойства человека более осозноваемы, чем глубинные убеждения, поэтому связь с копинг поведением более выраженная.

Практическая значимость заключается в выявлении представлений человека о себе, его убеждений и взаимосвязи их с поведенческим аспектом, который выражается в копинг поведении.

Ключевые слова: базисные убеждения, копинг стратегии, оценка личностных качеств.

\section{Основная часть}

В основе когнитивно-поведенчекой модели лежит теория, сформулированная Аароном Беком о том, что мыслительная деятельность и восприятие себя и окружающего мира определяется «когнитивными схемами». В когнитивной психотерапии понятия убеждения, схемы, правила, когнитивные паттерны, когниции в целом являются взаимозаменяемыми [9]

Изначально, Ф. Бартлетт, разработал понятие «схемы» определив ее как «бессознательная ментальная структура», которая дает представления или знания об окружающем мире. Более поздняя разработка понятия схемы Дж. Келли, привела к появлению термина «конструкт». Конструкт, в рамках теории данного автора, позволяет интерпретировать или предсказывать свой опыт и имеет форму мысли или идеи. Важный вклад в дальнейшую разработку понятия конструкта внес С. Эпштейн. В исследованиях, он доказал, что люди реконструируют реальность и себя в ней, двумя способами: рациональным и эмпирическим. Конструкты, построенные с помощью рациональной системы есть убеждения. Конструкты, 
формирующиеся эмпирическим путем, есть имплицитные убеждения или схемы.

В рамках когнитивно-поведенческого подхода под «когнитивной схемой» все чаще используется термин «глубинное убеждение», которые составляют основу концептуализации относительно самой личности и окружающего мира.

Механизм убеждения, как и представления о себе, других людях и мире, формируются у людей с детства. (Джудит Бек) Самые важные глубинные убеждения - это определенные интерпретации, которые так фундаментальны и глубоки, что люди не могут их четко сформулировать даже для себя. Человек относится к этим идеям как к истине в последней инстанции - они описывают, как все есть «на самом деле» (Beck, 1987).

Глубинные убеждения - самая фундаментальная форма убеждений; они глобальны, ригидны и чрезмерно обобщены.

Основная функция глубинных убеждений - успешная социальная адаптация индивида, возможная благодаря организации полученного опыта и пониманию себя и окружающего мира. (Rosen, 1988).

Дальнейшая разработка теории Яноффом-Бульманом, позволила сформулировать следующее определение: «базисные убеждения - имплицитные, глобальные, устойчивые представления индивида о мире и о себе, оказывающие влияние на мышление, эмоциональные состояния и поведение человека».

Убеждениям свойственна направленность: по отношению к себе, по отношению к миру и по отношению ко прошлому/будущему. [8]

Критерием для оценки убеждения можно выделить ее адаптивность: дезадаптивные убеждения - представления о себе и о мире, которые не ведут к успешной социальной адаптации, могут приводить к повышению тревожности и невротизации личности.

Убеждения реализуются в поведенческой сфере через копинг стратегии.

Копинг поведение, в глубинной основе своей - механизм социальной адаптации человека, формирующийся на самых ранних этапах онтогенеза, трансформирующийся и развивающийся по мере взросления человека.

На сегодняшний день, копинг поведение как феномен, изучен достаточно подробно.

Копинг-поведение понимается как сложный динами- ческий процесс, который начинается с оценки ситуации, включает когнитивные и поведенческие попытки ее преодоления, зависящие от личностных и ситуационных факторов.

Диспозициональный подход указывает на влияние личностных качеств на копинг поведение и преодоление стрессовых ситуаций.

Динамический подход сосредоточивает внимание на изучении изменчивых ситуационных факторов, а также когнитивных усилиях, направленных на управление внешним и внутренним факторам. [3]

Представители интегративного подхода, такие как Р.Моос, Дж. Шеффер, А. Биллнг рассматривают личностные и ситуационные факторы, как предикторы, влияющие на выбор копинг-усилий (Р. Моос, Дж. Шеффер (1993). Копинг в данном случае выступает одним из «аспектов способностей человека, который вместе с ресурсами служит преобразованию ситуации, устранению угрозы» (Р. Моос, А. Биллинг, 1982; Г. МакКуббин, 1987)

В Отечественной психологии копинг поведение переводится как совладающее поведение или адаптивное поведение. Совладающее поведение - это «целенаправленное социальное поведение, позволяющее субъекту справиться с трудной жизненной ситуацией (или стрессором) способами, адекватными личностным особенностям и ситуации - через осознанные стратегии действия» (Кочкарева 2013). Современная тенденция в вопросе копинг поведения проявляется в том, что пристальное внимание уделяется «психологическим чертам личности, обеспечивающим использование способов поведения, с помощью которых человек справляется с трудностями, несмотря на наличие тяжелых переживаний и вопреки длительному действию стресса» [2]

Но особенно важным, является внимательное изучение влияния личностных особенностей человека на копинг поведение. Результатом этого изучения может стать возможность человека: трансформировать представление о себе и окружающем мире, изменять самооценку и влиять на процесс социальной адаптации, варьируя свое поведение в зависимости от поставленных целей, ценностно-смысловых структур личности.

\section{Методологические исследования}

Гипотеза пилотажного исследования состояла, во-первых, в предположении о взаимосвязи между базисными убеждениями и стратегиями совладания, и во-вторых о взаимосвязи между личностными оценками себя и стратегиями совладания, в-третьих о том, что количество взаимосвязей зависит от направленности убеждения. 


\section{Шель исслеАования:}

Основной целью исследования было качественно проанализировать характер и направленность взаимосвязей между базисными убеждениями личности, оценкой личностных свойств и копинг стратегиями.

Выборка составила 70 студента Северо-Западного филиала РАНХиГС, студенты с первого по четвертый курс, очной и заочной форм обучения.

Среди них: 55 женщин, 15 мужчин. Средний возраст составил 21 год.

\section{Методы исследования:}

В качестве диагностического материала были использованы следующие методики:

1. Опросник «Способы совладающего поведения» Р. Лазаруса адаптирована Т.Л. Крюковой, Е.В. Куфтяк. Эмоционально ориентированные и проблемно-ориентированные фокус представлен следующим образом:

- Конфронтация

- Дистанцирование

- Поиск социальной поддержки

- Принятие ответственности

- Бегство-избегание

- Положительная переоценка

2. Методика Личностный дифференциал. Адаптирована сотрудниками психоневрологического института им. В.М. Бехтерева. Методика «Личностный дифференциал» состоит из 21 пары полярных прилагательных, через которые респонденты описывают представление относительно самого себя.

3. Шкала базисных убеждений - опросник, основанный на когнитивной концепции базовых убеждений личности. Разработана Ронни Янов-Бульман, адаптирована без стандартизации О. Кравцовой, затем адаптирована и рестандартизирована. Методика состоит из 8 шкал, в основе которых лежат базисные убеждения личности о: благосклонность мира, доброте людей, справедливость мира контролируемости мира, случайности как принципа распределения происходящих событий, ценности собственного «Я», степени самоконтроля (контроля над происходящими событиями), степени удачи, или везения.

Обработка результатов происходила на базе компьютерной программы JUSP.

\section{Основные результаты:}

Наибольшее количество корреляционных связей проявилось между оценкой личностных свойств и стратегиями совладания:

Значимые корреляционные связи проявились больше всего между:

«Бегство-избегание» и «нелюдимость» $\left(r=0,398^{*}, \mathrm{p}<0,001\right)$

Соответственно, чем больше человек характеризует себя как «нелюдимый», тем больше в его поведении проявляется стратегия избегания.

Стратегию «Бегство избегание» также реализуют респонденты, которые менее других уверены в себе $\left(r=-0,398^{*}, p<0.001\right)$. Обратная корреляция указывает на то, что чем меньше человек уверен в себе, тем чаще он использует данную стратегию.

Эта же стратегия имеет взаимосвязь с такой характеристикой как «деятельностный» $\left(r=0,415^{*}, p<0.001\right)$. Характеристика «Деятельностный» относится к фактору «Активность», что может говорить об интенсивность реализации данной стратегии в зависимости от оценки человеком себя.

Стратегия «Конфронтация» на уровне тенденции взаимосвязана с «Раздражительностью» $\left(r=0,243^{*}, p<0.05\right)$ Чем больше человек воспринимает себя как «раздражительный», тем больше он реализует в поведенческом аспекте стратегию конфронтации, что может приводить к высокой частоте конфликтов в его жизни и повышенному уровне стресса.

Стратегия «конфронтации» также имеет связь с такой характеристикой как «Разговорчивость» $(r=0,282 *$, $\mathrm{p}<0.05)$. Интерпретация такой взаимосвязи может выглядеть следующим образом: чем больше человек активен в коммуникации, тем чаще он применяет стратегию «конфронтации» имея возможность опираться на свой коммуникативный навык.

Важно обратить внимание на такое качество человека как «несамостоятельность».

В данном исследовании четко прослеживается, что такое определение себя вызывает 2 основные поведенческие стратегии: «Дистанцирование» ( $r=0,252 *$, $\mathrm{p}<0.05)$ и «Бегство-избегание» $\left(r=0,244^{*}, \mathrm{p}<0.05\right)$. Это достаточно тревожный факт, поскольку именно эти две стратегии считаются наименее эффективными стратегиями, которые человека могут приводить к социальной депривации.

Важно сказать, что «Уверенность» приводит человека к более эффективным, адаптивным стратегиям совладания, таким как «Планирование решение проблемы» $\left(r=0,288^{*}, p<0.05\right)$ 
Более выраженная взаимосвязь с качеством человека «Деятельный» и стратегией «Планирование решение проблемы» $\left(r=0,371^{*}, \mathrm{p}<0.001\right)$

Отрицательная корреляционная связь обнаружена между «черствостью» и «планированием решения проблемы». Таким образом, чем более человек себя интерпретирует как «черствый», тем менее реализуется данная стратегия. Планирование решение проблемы носит характер проблемно-ориентированной копинг стратегии, в то время как черствость как оценочный фактор указывает на «критическое отношение человека к самому себе, его неудовлетворенность собственным поведением, уровнем достижений, особенностями личности, на недостаточный уровень принятия самого себя»

Необходимо заметить что «черствость» также имеет еще одну взаимосвязь, которая носит более адаптивный характер: Поиск социальной поддержки» $\left(r=0,236^{*}, p<0.05\right)$

«Принятие отвественности» как стратегия совладания коррелирует с уверенностью человека в самом себе. $\left(r=0,364^{*}, p<0.01\right)$ Данная взаимосвязь очень важна для дальнейшей разработки исследования, поскольку ключ к формированию адаптивных стратегии совладания может находится в плоскости изменения «Я - образа»

«Самоконтроль» как стратегия показал взаимосвязи на уровне тенденции с «нелюдимостью» связан с такой оценкой себя как «расслабленностью» и замкнутостью, и разговорчивостью, и нелюдимостью. Отрицательная связь наблюдается с показателями нелюдимость и замкнутость, положительная - с расслабленностью и разговорчивостью.

Блок 2. Основывается на взаимосвязи между стратегиями совладания и убеждениями

Здесь важным является тот факт, что выявлена только одна корреляционная взаимосвязь. Планирование решения проблемы и справедливость этого мира $\left(r=0,428^{*}, p<0.01\right)$

Блок 3. По результатам корреляционного анализа между базисными убеждениями и оценкой личностных свойств выявлена единичная значимая взаимосвязь между убеждением о «ценности собственного Я» и «справедливостью мира». ( $r=0,289 *, p<0.05)$

\section{Основные выводы:}

1. Проведенное пилотажное исследование подтвердило гипотезу о том, что есть взаимосвязь между стратегиями совладания и индивидуальным, субъективным представлением о себе. Подтверждение гипотезы имеет большой практический смысл, поскольку понимание причинно-следственных связи дает возможность варьировать копинг поведение.

2. Качественный анализ результатов показал, что связи между оценочными личностными характеристиками и копинг стратегиями выражены сильнее, чем взаимосвязь между убеждениями и копинг стратегиями. Таким образом, мы можем сделать вывод о том, что все-таки взаимосвязь проявляется больше, когда направленность имеет внутренний, а не внешний характер.

Поскольку исследования проводилось не на клинической выборке, то убеждения можно назвать адаптивными. Адаптивные убеждения внешней направленности имеют меньшую выраженность по сравнению с оценка личностных свойств и копинг стратегиями.

\section{Б^агодарности}

Автор благодарит за помощь в написании работы научного руководителя доктора псих. наук, профессора Елену Владимировну Куфтяк и кандидата педагогических наук Ларису Львовну Карама за помощь в организации исследования на территории Северо-Западного филиала РАНХиГС.

\section{ЛИТЕРАТУРА}

1. Актуальные вопросы современной психологии материалы международной научной конференции: Совладающее поведение: аналитический обзор зарубежных исследований / А.Н. Гарбер//г. Челябинск, февраль 2015 г.). — Челябинск: с. 17-19.- материалы Междунар. науч. конференции

2. Крюкова Т.Л. Психология совпадающего поведения: современное состояние, проблемы, и перспективы» // Вестник Костромского государственного университета. Серия: Педагогика. Психология. Социокинетика. - Кострома. 2008 с-

3. Рогачев В.А. Коноплева И.Н. Взаимосвязь копинг-стратегий и личностных ресурсов стресс-преодолевающего поведения сотрудников правоохранительных органов // Медицинская психология в России. 2015. Выпуск №2

4. Падун М.А., Котельникова А.В. Модификация методики исследования базисных убеждений личности Р. Янофф-Бульман // Психологический журнал № 29(4), 200798 - 106

5. Фетискин Н.П., Козлов В.В., Мануйлов Г.М. Социально-психологическая диагностика развития личности и малых групп: учеб. пособие для студентов вузов. Москва, 2002. 339 C. 
6. Шматова Ю.Е. Динамика статистических и социологических показателей состояния психического здоровья населения России. // Проблема развития территории 2019г. №3 3.76

7. Райгородский Д.Я. Практическая психодиагностика. Методики и тесты. Учебное пособие. / Самара: «Бахрах-М», 2001)

8. Яковлев М.И. Влияние отношений личности к прошлому, настоящему и будущему на развитие личностного самоопределения специалиста в процессе профессионального становления // Сибирский педагогический журнал. 2009. №4

9. Bartlett F.S. Remembering: A Study in Experimental and Social Psychology. Cambridge: Cambridge University Press, 1932. 374p.

10. Judith. Beck «Cognitiv Therapy» Пер. с англ. - М.: 000 «И.Д. Ви- льямс», 2006. 110 р.

11. Aaron Beck, Arthur Freeman. Cognitive Therapy of Personality Disorders, 1990. 412p.

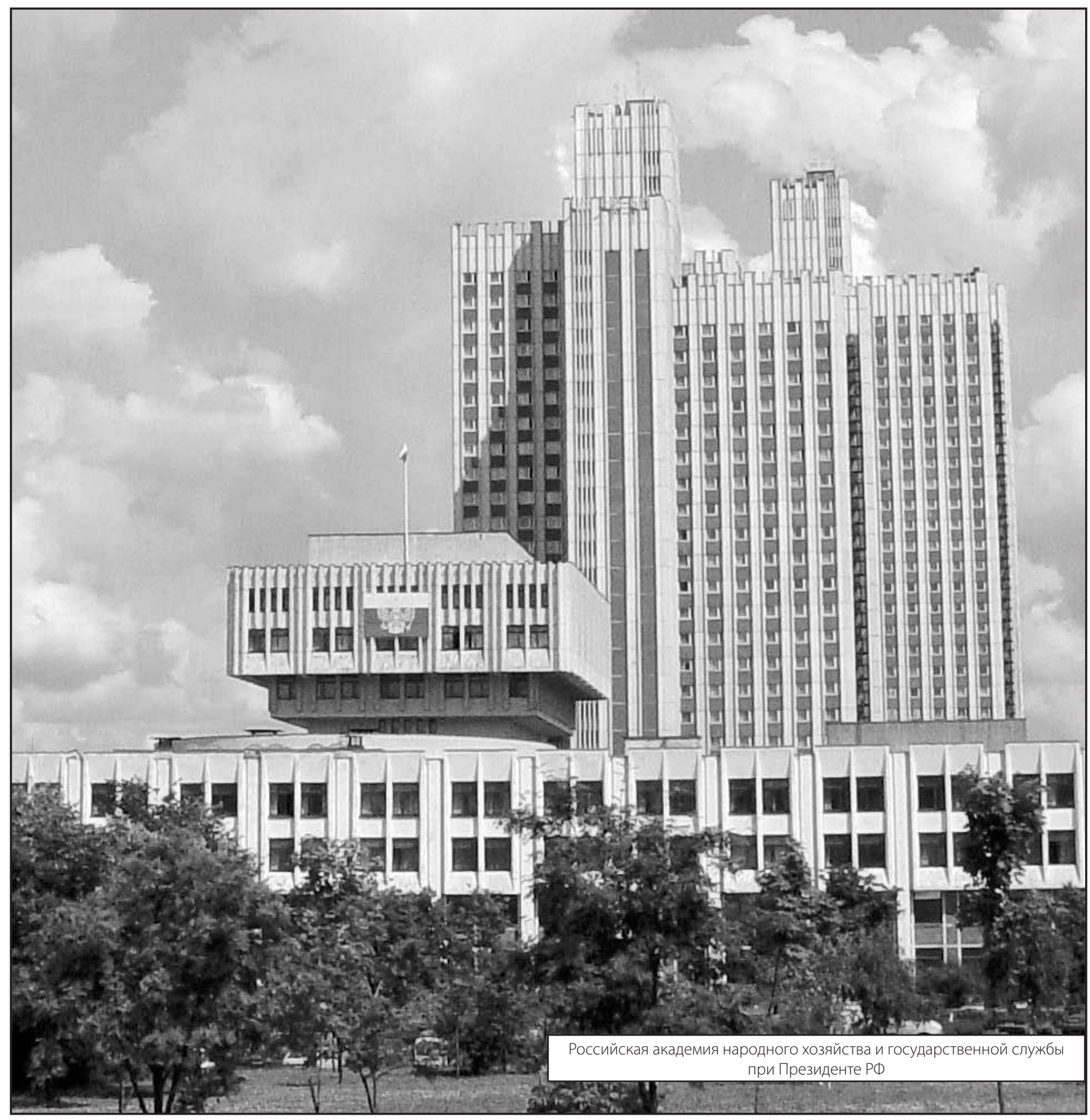

